\title{
COMPLICATIONS DURING NEUROSURGERY IN THE PRONE POSITION IN CHILDREN
}

\author{
H.W. MeRiDY, M.D., F.A.C.A., ${ }^{\circ}$ R.E. CREIGHTON, M.D., F.R.C.P.(C) ${ }^{\circ}$ \\ AND R.P. HUMPHREYS, M.D., F.R.C.S. (c) $\dagger$
}

LESIONS IN THE POSTERIOR CRANIAL fOSSA and upper cervical region present a difficult problem to the anaesthetist. Air embolism and surgical damage to vital medullary centres are the main dangers.

This paper presents the complications found in a retrospective study of 120 consecutive operations in the prone position, for lesions in the posterior cranial fossa and upper cervical region.

\section{Clinical Material}

One hundred and seven patients underwent 120 operations on the posterior fossa or upper cervical region at The Hospital for Sick Children, Toronto, between 1969 and 1971.

There were 44 primary tumours of the posterior fossa: astrocytoma (19), medullablastoma (9), ependymoma (7), glioma (7), ganglioglioma (1), and cerebellar sarcoma (1). Eight patients underwent re-operation for tumour of the posterior fossa. Twenty-three patients had closure of a posterior encephalocoele or encephalomeningocoele.

Five patients had resection of an occipital dermoid. Posterior fossa decompression was performed for Arnold Chiari malformation (6), arachnoid adhesions (4), cerebellar hypertrophy and hyperplasia (1), cerebellar oedema (1), arachnoid cyst (1), and achondroplastic dwarf (1). Miscellaneous posterior fossa procedures included intramedullary meningocoele (1), aneurysm of posterior-inferior cerebellar artery (1), repair of dural tear (1), elevation of depressed skull fracture (1), evacuation of post-operative haematoma (1), and exploration of an infected sinus tract after excision of a dermoid cyst (1). One patient had a negative exploration for suspected tumour.

Three patients had occipital burr holes following trauma and one for diagnosis (neurofibromatosis). There were seven tumours of the cervical cord: neurolemmoma (2), extradural neurofibroma (1), astrocytoma (1), intramedullary ganglioglioma (1), and rhabdomyosarcoma (1). One patient underwent re-operation for cervical cord tumour; two patients had closure of cervical meningocoele.

Miscellaneous causes for cervical laminectomy included: syringomyelia or hydromyelia of the cord (2), A-V malformation (1), evacuation of post-operative haematoma (1), traumatic fracture (1), and cord compression following old injury (1).

Forty-two patients with raised intracranial pressure had a ventriculo-peritoneal

From the Department of Anaesthesia ${ }^{\circ}$ and the Division of Neurosurgery, $f$ University of Toronto and Hospital for Sick Children, Toronto. 
shunt performed following investigative ventriculography. The shunts were performed on an average of 13 days prior to surgery to decompress the posterior fossa. These cases included 34 primary posterior fossa tumours, 3 encephalocoeles, 2 Arnold Chiari malformations and 9 described as miscellaneous. In addition, 6 patients had a pre-existing ventriculo-peritoneal shunt.

\section{Anaesthetic Techniques And Agents}

Atropine sulphate $(0.02 \mathrm{mg} / \mathrm{kg})$ was given as premedication to all the patients. Infants under one month were pre-oxygenated and intubated before anaesthesia was induced. In older patients anaesthesia was induced with intravenous thiopentone $(4-5 \mathrm{mg} / \mathrm{kg})$ and succinylcholine $(1 \mathrm{mg} / \mathrm{kg}$ ) before intubation. The majority of patients had a Portex nasotracheal tube. Where this was not feasible, armoured orotracheal tubes were used. All patients were placed prone with transverse bolsters under the shoulders and pelvis. The head was positioned on a horseshoe frame and the operating table adjusted to $15^{\circ}-20^{\circ}$ of anti-Trendelenburg. The patients were monitored with an oesophageal stethoscope, blood pressure cuff, electrocardiograph and rectal thermistor. Neither a right heart catheter nor precordial Doppler apparatus was used, so the true incidence of air embolism was not determined.

Since the majority of patients weighed under $50 \mathrm{~kg}$ a high flow Ayre's T-piece system was used. A circle filter system was used in the larger children. Respiration was spontaneous or controlled depending on the preference of the surgeon. Maintenance agents for spontaneous respiration were $\mathrm{N}_{2} \mathrm{O}$ (66 per cent), halothane ( 0.5 per cent) and trichloroethylene ( 0.5 per cent). The concentration of trichloroethylene was reduced during the operation and the agent was eliminated entirely at least 30 minutes before completion. $\mathrm{N}_{2} \mathrm{O}$ (66 per cent) and halothane (1.5-1.0 per cent) alone were used when a circle filter was employed. Maintenance agents for controlled ventilation were either $\mathrm{N}_{2} \mathrm{O}$ ( 66 per cent) and halothane $(0.5$ per cent), or $\mathrm{N}_{2} \mathrm{O}$ ( 66 per cent) alone with d-tubocurare (muscle relaxant). In the older children Innovar ${ }^{*}(1 \mathrm{ml} / 25 \mathrm{~kg})$ was given prior to surgery if the $\mathrm{N}_{2} \mathrm{O} /$ curare technique was employed. An Air-Shields ventilator was used with both positive and negative $\left(-4 \mathrm{cmH}_{2} \mathrm{O}\right)$ phase and adjusted by blood gas analysis to give an arterial $\mathrm{P}_{\mathrm{CO}_{2}}$ approximating $30 \mathrm{~mm} \mathrm{Hg}$.

The method of ventilation in operations on posterior fossa and cervical tumours is given in Table I. Ventilation was changed from spontaneous to controlled during twelve operations because of cardiac arrhythmias (6), respiratory difficulties (3), cardiac arrest (1), air embolism (1), and technical difficulties (1).

\section{BLood Replacement}

As there was no accurate measure of blood loss the systolic blood pressure was monitored and blood was given to maintain systolic blood pressure at $70 \mathrm{~mm} \mathrm{Hg}$ in infants and $80 \mathrm{~mm} \mathrm{Hg}$ in older children. After surgery was completed and before

\footnotetext{
-Innovar : McNeil Laboratories of Canada, Don Mills, Ontario.
} 


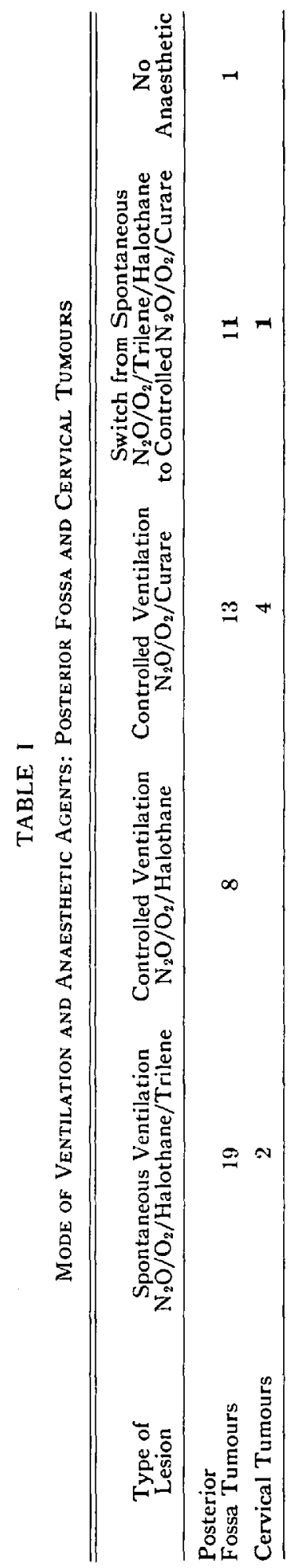


the dura was closed, enough blood was given to return the systolic blood pressure to the pre-loss value. An additional 10 per cent of the estimated blood volume was then given during the closure.

\section{Blood Loss Estimation}

Assuming that blood volume is constant we can say that:

Total haemoglobin $(\mathbf{H g b})$ lost $=$ (Total pre-operative $\mathrm{Hgb})+($ Total transfused $\mathrm{Hgb}$ ) - (Total $\mathrm{Hgb}$ on the first post-operative day).

The percentage blood loss was estimated as follows:

Total Hgb lost/Total pre-operative Hgb $\times 100=\%$ blood loss

Since post-operative neurosurgical patients are normally on a restricted fluid intake, the value for post-operative haemoglobin is probably affected by haemoconcentration and this method would therefore give a conservative estimate of blood loss. However, it allows for a comparison of different techniques.

Table II suggests that during excision of posterior fossa tumours the blood loss is decreased by the use of controlled ventilation.

TABLE II

Blood Loss During Excision of Posterior Fossa Tumours

\begin{tabular}{lc}
\hline \multicolumn{1}{c}{ Mode of Ventilation } & \% of Estimated Blood Volume \\
\hline Spontaneous Breathing & 22 \\
Controlled Breathing & 18 \\
Spontaneous to Controlled & 23 \\
\hline
\end{tabular}

\section{INTRAOPERATIVE COMPLICATIONS}

Cardiac arrhythmias occurred in ten patients. Manipulation and resection (6) or needling (2) of a brain stem tumour was the cause in eight instances. One of these patients also developed an arrhythmia during re-operation for removal of a post-operative blood clot. Pre-operative infiltration with $1: 200,000$ adrenalin produced the other arrhythmia. Ventricular ectopic beats were the commonest abnormality. These occurred in six instances and were associated with bradycardia in two, tachycardia in one and bigeminal rhythm in another. In three instances the sole arrhythmia was bradycardia and in one, tachycardia.

Cardiac arrhythmia developed in five patients on controlled ventilation with $\mathrm{N}_{2} \mathrm{O} / \mathrm{O}_{2} /$ curare. One of these patients had developed irregular shallow respirations during manipulation of the tumour and was placed on controlled ventilation 30 minutes prior to the occurrence of the cardiac arrhythmia.

In five other instances the patient was switched from spontaneous to controlled respiration when the arrhythmia occurred. Unfortunately, one of these patients did not recover spontaneous respiration post-operatively. One patient required intravenous propranolol to control tachycardia and another with tachycardia and ventricular ectopic beats received intravenous lidocaine. The arrhythmia in the remainder disappeared following the institution of controlled ventilation or the 
interruption of surgery. In 6 of these 10 instances the patient did not have a functioning ventriculo-peritoneal shunt performed pre-operatively.

Respiratory complications occurred in four patients. Respirations became shallow and irregular during manipulation of a brain stem tumour in one and in another, with an Arnold Chiari malformation, when the head was flexed prior to surgery. A third patient became apnoeic because of raised intracranial pressure, and spontaneous respiration returned only after the CSF was released from the cisterna magna. The fourth patient, who was placed on controlled respiration following development of a cardiac arrhythmia, did not recover spontaneous respiration post-operatively.

There were three cardiac arrests. One occurred when the operative site was packed with hot sponges after excision of an ependymoma adherent to the floor of the IVth ventricle. The arrest responded to closed cardiac massage. A second occurred during an emergency decompression in a patient with a medulloblastoma who had an undiagnosed massive gastrointestinal bleed from a steroid stress ulcer. He could not be resuscitated. The third patient was having emergency posterior burr holes made after a multiple trauma accident and had a large retroperitoneal haematoma. Post-mortem examination revealed pulmonary emboli of brain tissue as well as skull fractures and a laceration of the right renal artery.

There were two possible air emboli. During a laminectomy from $C_{2}$ to $T_{6}$ for excision of an intramedullary ganglioglioma, a 10-year-old child developed a systolic murmur, hypertension and a bigeminal rhythm with multiple ectopic beats. Ventilation was switched from spontaneous to controlled and the cardiac abnormalities disappeared within three minutes. There were no sequelae. A second patient, during a posterior fossa decompression for an Arnold Chiari malformation, exhibited a sudden bradycardia ( 120 to 10 per minute). External massage and an isoproterenol drip resulted in an adequate cardiac rate and there were no sequelae.

Two patients experienced technical problems. In one patient a tense dura developed owing to secretional obstruction of the tracheal tube; this was corrected with aspiration of the tube and controlled ventilation. One patient with an orotracheal tube, which was secured with a new type of adhesive tape, had an accidental extubation. Both patients recovered without complication.

All infant patients for closure and repair of occipital encephalocoele experienced a temperature drop. In three instances (ages 2 days, 2 days and 3 days) this was greater than $3^{\circ} \mathrm{C}$. All recovered without complication.

\section{Discussion}

Many anaesthetists and neurosurgeons advocate the sitting position for posterior fossa exploration. ${ }^{1-12}$ Such positioning provides an excellent view of the posterior cranial fossa with the operative site situated at the surgeon's eye level. In this position gravity effectively drains spinal fluid and blood from the operative wound. It also facilitates venous return to the heart, relieving intracranial venous stagnation and so controlling venous pressure and ooze, and ultimately brain swelling. 
Many anaesthetists and surgeons $s^{4,5,8,10,12-15}$ are fully aware of the disadvantages of the sitting position. Such pitfalls include the risk of venous air embolism, cardiovascular instability leading to systemic hypotension and diminished cerebral blood flow, the possibility of the patient sliding down the table during operation and difficulty with temperature control.

In children, most posterior fossa and upper cervical spine surgery is also done with the child sitting. ${ }^{8,0,12}$ However, in children less than two years of age the prone position is recommended. ${ }^{8}$ Our preference has been to use the prone position for all children undergoing posterior fossa and upper cervical surgery.

The fact that the neurosurgeon operates on the medullary centres of the brain in posterior fossa explorations makes anaesthesia for these procedures potentially dangerous. Aside from the cardiac and respiratory dysrhythmias that can arise from surgical manipulation of this area of the brain, blood loss and air embolism are frightening iatrogenic complications.

It is argued that the sitting position permits gravity drainage of blood and spinal fluid from the operative wound. But gravity makes the structures of the posterior fossa dependant, in particular the cerebellar hemispheres which enjoy communication through the superior and inferior cerebellar veins with adjacent venous sinuses. One is sometimes faced with continuous venous bleeding from the superior surface of the cerebellum after a posterior fossa mass lesion has been excised. This bleeding is frequently due to tearing of a communicating vein when the cerebellar hemispheres sag after the tension has been relieved.

A further argument against the sitting position is the fact that it will further diminish cerebral blood flow, which may already have been reduced by hyperventilation. ${ }^{14}$ The hydrostatic effect in the sitting position is also important. The pressure at the base of the skull will be less than pressure at the level of the arm. ${ }^{17}$ Naturally this hypotensive effect with alteration in cerebral blood flow can be seriously aggravated by small amounts of blood loss in a paediatric neurosurgical patient.

The creation of a ventriculo-peritoneal shunt at the time of investigative ventriculography resulted in several advantages in our experience. It allowed major operations to be scheduled electively, on an average of 13 days later. During this time the patients' fluid and nutritional status was improved. The operative site was less compressed and congested at the time of operation and the post-operative problems of raised intracranial pressure were eliminated. It is hoped that the use of a millipore filter in the shunt system has removed the danger of tumour seeding in the abdomen. ${ }^{16}$

In our series blood loss was less in patients in whom controlled rather than spontaneous ventilation was used. Michenfelder now relies solely upon changes in cardiac rate and rhythm to detect dangerous manipulation of vital medullary centres. ${ }^{15}$ However, one of our patients experienced respiratory changes requiring controlled ventilation 30 minutes prior to the development of a cardiac arrhythmia which led to abandonment of surgery. In another patient, who had been placed on controlled ventilation because of a cardiac arrhythmia, post-operative spontaneous respiration was not recovered. The respiratory monitor of spontaneous respiration may still be important during surgical treatment of brain stem lesions. 
While air embolism has reportedly complicated neurosurgical procedures in the supine and prone positions, it is allegedly more common in patients operated upon in the sitting position. ${ }^{4,5,18,18}$ While the threat of air embolism is not entirely removed with the patient positioned prone, it is considerably lessened. ${ }^{18}$ There were two suspected cases of air emboli in our series of 120 operative procedures ( 1.7 per cent). This compares favourably with a number of reports in the literature. Hunter reported on three cases of air emboli in patients operated in the sitting position. He concluded that even effective positive pressure ventilation does not eliminate this problem. ${ }^{5}$ Marshall cited a 15 per cent incidence of air emboli in posterior fossa exploration made with the patient in the sitting position and breathing spontaneously; and 2.4 per cent incidence in cervical laminectomies made with the patient in the prone position and breathing spontaneously. No air emboli were observed by Marshall when positive-negative ventilation was used. ${ }^{18}$ Leivers et al. report a 4.6 per cent incidence of air emboli in patients undergoing posterior fossa explorations in the sitting position with controlled ventilation. ${ }^{20}$ Michenfelder et al. during a seven-year period observed a 2 per cent incidence in 2,002 neurosurgical procedures done with the patient in the sitting position. ${ }^{21}$ Using an ultrasonic detecting device, these investigators confirmed that the incidence rose to 6 per cent. ${ }^{19}$ Because of the richly vascularized occipital bone and the ill-defined and extensive dural venous sinuses in the infant and young child, greater emphasis must be placed upon reducing the threat of venous air embolism. In our experience the incidence of clinically significant venous air embolism is low in patients undergoing posterior fossa explorations in the prone position.

Manipulation of the medullary centres of the brain is known to produce cardiac and respiratory dysrythmias. Whitby observed that cardiac irregularities alone occurred in 51 per cent of adult patients in his series undergoing posterior fossa exploration. ${ }^{22}$ In this series of paediatric patients a cardiac or respiratory abnormality developed intra-operatively in 14 per cent of the cases.

Although in five instances the cardiac arrhythmia disappeared when the patient was switched to controlled ventilation, the fact that one patient did not recover spontaneous respiration post-operatively indicates the danger of disregarding this important sign and proceeding with surgical resection of a tumour in an area intimately associated with the vital centres.

This retrospective study has led to the following changes in our technique of management of lesions in the posterior cranial fossa and upper cervical region. First, in an effort to reduce blood loss, more attention is now paid to positioning of the patient to ensure that the abdomen is free from any compression. Second, after being positioned, the patient is placed on controlled positive and negative ventilation. If vital centres are likely to be manipulated after the dura is opened and the surgeon requests spontaneous ventilation, 10 per cent carbon dioxide is added to the anaesthetic gas mixture for 90 seconds to restart spontaneous respiration. If an Ayre's T-piece has been used, 5 per cent trichloroethylene is also added. If a circle filter is used, the concentration of halothane is increased to $1.0-1.5$ per cent as required. After completion of the surgical excision controlled ventilation with nitrous oxide and 0.5 per cent halothane is re-instituted until completion of the closure. 


\section{SUMMARY}

The authors reviewed the charts of 107 patients undergoing surgery (in the prone position) for posterior fossa or upper cervical lesions. The use of controlled ventilation appeared to reduce the blood loss. The creation of a ventriculo-peritoneal shunt on an average of 13 days before surgery improved operative conditions and decreased the incidence of intra-operative complications during posterior fossa operations. The prone position with or without controlled ventilation resulted in good surgical conditions and had some anaesthetic advantages.

\section{RésUMÉ}

Les auteurs présentent les résultats d'une analyse des dossiers de 107 enfants ayant subi en position ventrale 120 interventions au niveau de la fosse postérieure ou au niveau de la colonne cervicale.

Ils ont relevé des complications respiratoires et cardiaques (troubles du rythme et arrêts cardiaques), des embolies aériennes, des chutes de température et des problèmes techniques.

La création d'un shunt ventriculo-péritonéal préalable à la chirurgie améliorait les conditions opératoires.

L'usage de ventilation contrồlée semblait diminuer les partes sanguines.

Les auteurs concluent que la position ventrale chez ces patients, associée ou non à une respiration contrôlée a résulté en des conditions opératoires satisfaisantes et semble avantageuse du point de vue anesthésique.

\section{REFERENCES}

1. Bucy, P.C. Exposure of the posterior or cerebellar fossa. J. Neurosurg. 24: 820 (1966).

2. Drake, C.G. Total removal of large acoustic neuromas. A modification of the McKenzie operation with special emphasis on saving the facial nerve. J. Neurosurg. 26: 554 (1967).

3. Hankunson, J. Posterior fossa tumors. In Operative Surgery, Vol. 14. Logue, Ed. London: Butterworths, p. 113 (1971).

4. Honowitz, N.H. \& RizzolI, H.V. Postoperative complications in neurosurgical practice. Baltimore: The Williams \& Wilkins Co., p. 427 (1967).

5. Hunter, A.R. Air embolism in the sitting position. Anaesthesia 17: 467 (1962).

6. Kahn, E.A., Crosby, E.C., Schneider, R.C., \& Taren, J.A. Correlative neurosurgery. 2nd ed. Springfield: Charles C. Thomas, p. 693 (1969).

7. Kempe, L.G. Operative neurosurgery. Vol. 2. Posterior fossa, spinal cord and peripheral nerve disease. New York: Springer-Verlag, p. 281 (1970).

8. Koos, W.T. \& Miller, M.H. Intracranial tumors of infants and children. St. Louis. C.V. Mosby Company, p. 415 (1971).

9. Ingraham, F.D. \& Matson, D.D. Neurosurgery of infancy and childhood. Springfield: Charles C. Thomas, p. 934 (1961).

10. Symon, L. Control of intracranial tension. In operative surgery. Neurosurgery. Logue, Ed. London: Butterworths, p. 1 (1971).

11. Yasargil, M.G. Microsurgery applied to neurosurgery. Stuttgart: George Thieme. Verlag, p. 230 ( 1969 ).

12. Allan, D., Kim, H.S., \& Cox, J.M. The anaesthetic management of posterior fossa explorations in infants. Can. Anaesth. Soc. J. 17: 227 (1970).

13. McСomish, P.B. \& BodLey, P.O. Anaesthesia for neurological surgery. Chicago: Year Book Medical Publishers, p. 412 (1971). 
14. Tindali, G.T., Craddocx, A., \& Greenfield, J.C. Jr. Effects of the sitting position on blood flow in the internal carotid artery of man during general anaesthesia. J. Neurosurg. $26: 383$ (1967).

15. Michenfelder, J.D., Gronert, G.A., \& Rehder, K. Neuroanesthesia. Anesthesiology 30: 65 (1969).

16. HofFMan, H.J. Personal communication.

17. Michenfelder, J.D. \& TeRRY, H.R. JR. Current practices and trends in neuroanesthesia. Clin. Neurosurg. 13: 252 (1965).

18. Marshatl, B.M. Air embolus in neurosurgical anaesthesia, its diagnosis and treatment. Can. Anaesth. Soc. J. 12: 255 ( 1965 ).

19. Michenfelder, J.D., Miller, R.H., \& Gronert, G.A. Evaluation of an ultrasonic device (Doppler) for the diagnosis of venous air embolism. Anesthesiology 36: 164 (1972).

20. Leivers, D., Spilsbury, R.A., \& Young, J.V.I. Air embolism during neurosurgery in the sitting position, Two Case Reports. Br. J. Anaesth. 43: 84 (1971).

21. Michenfelder, J.D., Martin, J.T., Altendurg, B.M., \& Rehder, K. Air embolism during neurosurgery. J.A.M.A. 208: 1353 ( 1969).

22. WhITBY, J.D. Electrocardiography during posterior fossa operations. Br. J. Anaesth. 35: 624 (1963). 